\title{
Semantic gender assignment regularities in German
}

\author{
Beate Schwichtenberg $^{\mathrm{a}}$ and Niels O. Schiller ${ }^{\mathrm{b}, \mathrm{c}, *}$ \\ ${ }^{a}$ Department of Cognitive Science, University of California, San Diego, CA, USA \\ ${ }^{\mathrm{b}}$ Department of Neurocognition, Faculty of Psychology, University of Maastricht, NL-6200 MD, Maastricht, The Netherlands \\ ${ }^{\mathrm{c}}$ Max Planck Institute for Psycholinguistics, Nijmegen, The Netherlands
}

Accepted 3 December 2003

Available online 31 January 2004

\begin{abstract}
Gender assignment relates to a native speaker's knowledge of the structure of the gender system of his/her language, allowing the speaker to select the appropriate gender for each noun. Whereas categorical assignment rules and exceptional gender assignment are well investigated, assignment regularities, i.e., tendencies in the gender distribution identified within the vocabulary of a language, are still controversial. The present study is an empirical contribution trying to shed light on the gender assignment system native German speakers have at their disposal. Participants presented with a category (e.g., predator) and a pair of gender-marked pseudowords (e.g., der Trelle vs. die Stisse) preferentially selected the pseudo-word preceded by the gender-marked determiner "associated" with the category (e.g., masculine). This finding suggests that semantic regularities might be part of the gender assignment system of native speakers.
\end{abstract}

(C) 2003 Elsevier Inc. All rights reserved.

Keywords: Speech production; Semantic categories; Gender assignment rules; Gender decision; German

\section{Introduction}

What do native speakers know about grammatical gender? This question has received wide attention within linguistic (e.g., Corbett, 1991) and psycholinguistic (e.g., Schriefers \& Jescheniak, 1999) research. One approach to this question is to analyze the mechanisms that speakers use to choose the gender of a noun. Many psycholinguistic studies have investigated the gender retrieval mechanism, which is the mechanism by which grammatical gender is accessed during the preparation of an utterance (for a review, see Caramazza, Miozzo, Costa, Schiller, \& Alario, 2001). The underlying assumption is that a noun's gender is stored in the mental lexicon because gender seems to be an arbitrary feature of nouns. For example, the concept CAR is feminine in French (la voiture), masculine in Spanish (el coche), neuter in German (das Auto), and has common gender in Dutch (de auto).

\footnotetext{
${ }^{*}$ Corresponding author. Fax: +31-43-3884125.

E-mail address: n.schiller@psychology.unimaas.nl (N.O. Schiller).
}

However, the mechanisms of gender assignment have been neglected in psycholinguistic research. The gender assignment system refers to a native speaker's knowledge about the structure of the gender system of his/her language, allowing the speaker to select a gender even when he uses words which are not part of his lexicon and for which therefore no gender is stored (e.g., for new words). The assumption here is that speakers have access to a system of rules and regularities, which may support their gender selections.

The present study deals with one part of the assignment system in German, i.e., semantic gender assignment regularities. Gender assignment differs quite a bit between languages (Corbett, 1991). Here, we restrict the discussion to German because results obtained in other languages need not generalize to German. In the following, we first give a short overview of the gender system in German and of Corbett's definition of gender assignment (see also Corbett, 1991). Then we review experimental evidence and two approaches to the question of how speakers know the gender of a noun, i.e., the theory of lexical access by Levelt, Roelofs, and Meyer (1999) (Levelt, 1989, 2001) and the gender as- 
signment approach of Köpcke and Zubin (Köpcke, 1982; Köpcke \& Zubin, 1983, 1984, 1996; Zubin \& Köpcke, 1984a, 1984b, 1986).

German has a gender system with three genders, i.e., masculine, feminine, and neuter. The genders are not marked on the nouns themselves, but rather on determiners and other parts of speech which occur within the same noun phrase (NP) as the noun. The definite determiners corresponding to the three genders are der $\left(\right.$ the $\left._{\text {mas }}\right)$, die $\left(\right.$ the $\left._{\text {fem }}\right)$, and das $\left(\right.$ the $\left._{\text {neu }}\right)$. For instance, das Brot 'the $_{\text {neu }}$ bread' is neuter, die Butter 'the fem $_{\text {fem }}$ butter' is

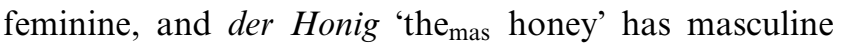
gender. ${ }^{1}$ The genders in German are fairly equally distributed: If word frequency is taken into account, neuter gender $(26 \%)$ occurs only slightly less often than masculine $(39 \%)$ and feminine $(35 \%)$ gender (Schiller \& Caramazza, 2003).

According to Corbett (1991) there are two approaches to the question of how speakers know which gender to select for a noun, lexicalization, and computation of gender. The "lexicalization of gender" approach claims that for all nouns the gender is stored in the lexicon. A speaker needs to retrieve the gender when a gender-marked utterance is to be produced. However, Corbett argues against the lexicalization of gender. First, native speakers do not usually make errors in gender assignment for words they know. If the gender of all words were memorized, occasional assignment errors might be expected to occur due to memory failure. Second, when native speakers use new or borrowed words, they are able to assign a particular gender to those words. Moreover, gender assignment to novel words does not occur in a random manner. On the contrary, speakers agree to a large degree on the gender they assign to a new word.

Lexicalization of gender is one of the claims of the theory of lexical access in speech production put forth by Levelt et al. (1999). In this theory, the production of a word requires four serial encoding stages: conceptual encoding, syntactic encoding, wordform encoding, and articulation. In the conceptual encoding process, a lexical concept that corresponds to the intended meaning has to be selected. During syntactic encoding, the lexical concept activates its lemma (i.e., a collection of all syntactic features for a lexical concept). For instance, word class is a syntactic feature that is marked at the lemma level. For nouns, gender is another syntactic feature encoded at the lemma level. The third encoding stage is wordform encoding. During this encoding step, morphological and phonological information is retrieved and processed to yield a sound representation of the word. Finally, articulatory motor programs might be

\footnotetext{
${ }^{1}$ We will use the following abbreviations throughout the paper: mas $=$ masculine, fem $=$ feminine, and neu $=$ neuter
}

constructed which can be used to control the movements of the speech organs during overt articulation.

Gender is represented as a lexico-syntactic feature in Levelt et al.'s theory of speech production. The lemma node is connected to an abstract gender node, specifying one of a language's genders. The connection between the lemma node and the gender node is the same kind for all nouns, which implies two things. First, the gender assignment mechanism is seen as a uniform mechanism, i.e., there is only one type of connection, which is the same for all nouns. Second, all genders are considered to be lexicalized, as opposed to being computed in the production process. These assumptions are plausible within the domain of moderate to high-frequency nouns, and maybe somewhat less for low-frequency nouns. However, the "lexicalization view" does not provide an account of how to assign gender to new nouns (like borrowings from another language, e.g., Computer $r_{\text {mas }}$ in German).

Corbett (1991) suggested "computation of gender" as an alternative to lexicalization. According to this approach gender does not have to be stored in the lexicon because the gender system is highly structured, and there is a set of rules and regularities that govern the selection of gender. This set is the gender assignment system, and it can be used to derive the gender of nouns. Corbett lists both lexicalization and computation as possible gender assignment mechanisms. However, here the term assignment will be used to refer to the computation of gender based on rules and regularities, unless explicitly stated otherwise.

Köpcke and Zubin (Köpcke, 1982; Zubin \& Köpcke, 1984a, 1986) analyzed the gender distribution in the German vocabulary and found a highly structured gender system. They claimed that the systematic character of the gender distribution in German is a reflection of the gender assignment system. Köpcke and Zubin have identified three different mechanisms for gender assignment: rules, regularities, and exceptions. Rules categorically assign gender mostly without exceptions within their domain of application. For instance, the last member principle is a rule used to assign gender to a large fraction of the morphologically complex nouns. It requires complex nouns have the gender of their last morpheme (i.e., the lexical head in German). For in-

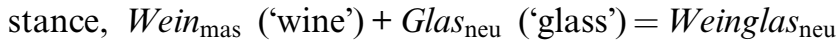
('wineglass'). As far as exceptions to rules and regularities are concerned, not much is to be said here. The gender of exception nouns must be lexicalized, as there is no way to derive the gender of these nouns by rules or regularities.

The regularities within the gender assignment system are of most interest in this study. The term regularity is used to refer to a preference of one gender within the domain of its application. Regularities state that the probability of a noun having a specific gender within the application domain of the regularity is high although 
exceptions are frequent. Köpcke and Zubin (1983) referred to regularities as stochastic rules. To avoid confusion with the term (categorical) rule, we adopt the term regularity in this paper. By means of vocabulary analyses, Köpcke and Zubin identified an extended set of gender assignment regularities in the phonological, morphological, and semantic domain in the German lexicon.

Köpcke (1982) examined the phonological basis of the gender distribution in German. The analysis was restricted to monosyllabic nouns. This restriction was motivated by the long-standing assumption of arbitrariness within the gender distribution of these German nouns (discussed in detail in Köpcke, 1982). For morphologically complex nouns, the last member principle governs the gender distribution, and strong tendencies based on the phonological form exist for monomorphemic polysyllabic words (e.g., $-e$ generally marks feminine gender). Köpcke identified 24 phonological gender regularities for monosyllabic nouns and used them to algorithmically predict gender in a corpus of monosyllabic nouns. An example for a phonological regularity is the consonant cluster principle, which states that the more consonants occur in the onset and coda of a monosyllabic noun, the more likely the word is to have masculine gender.

As to morphological regularities in the gender distribution, mainly plural and genitive case formations are mentioned (e.g., Köpcke, 1982). For instance, German nouns that form the plural in $-(e) n$ tend to be feminine. Bittner (1999) argues that this systematic relation of gender and nominal inflectional class may not be part of the assignment system. As part of the assignment system, native speakers would need to use the inflectional class to predict gender. Bittner suggests that the relation is the reverse: Native speakers use gender to predict the inflectional class.

The most obvious semantic basis in the gender distribution is the "natural gender (or perceived sex) principle" which states that male human beings are assigned masculine, and female human beings feminine gender (Köpcke \& Zubin, 1996). The natural gender principle is the semantic core of the assignment system (Corbett, 1991). However, the present study does not deal with natural gender, but with other, less wellknown semantic regularities in the gender system.

For basic level terms, Zubin and Köpcke (1984a, 1986) identified four types of semantic regularities: simple classifications, classification with inner structure, complex classification, and classification along a continuum. Simple classifications (or direct gender associations) refer to the preferred (or even exclusive) use of one gender within a semantic field. For instance, there is an association between color names and neuter gender in German (e.g., das Blau 'the neu blue,' das Rot 'the $_{\text {neu }}$ red,' etc.). By contrast, gender is said to reflect the inner structure of a semantic field when different sub-fields take different genders. This type of classification occurs with beverages: While alcoholic beverages in general have masculine gender in German (e.g., der Wein 'the mas wine'), all kinds of beer (e.g., das Bier 'the neu $_{\text {beer') have }}$ neuter gender. Non-alcoholic beverages (e.g., der Saft

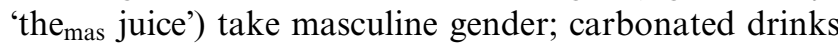
(e.g., dieldas Sprite 'the fem $/$ the $_{\text {neu }}$ sprite') have varying feminine and neuter gender. The so-called complex classification occurs when a category is semantically associated with a gender, but phonological gender regularities override the associated gender. In case no other regularity applies, the semantically associated gender is used. For instance, birds have masculine gender unless phonological and morphological cues towards feminine gender are present (e.g., der Adler 'the $\mathrm{m}_{\text {mas }}$ eagle,' but die

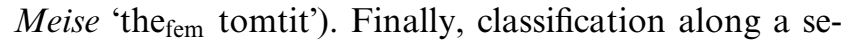
mantic continuum occurs when two opposite poles, which are associated with different genders, define a semantic continuum. Whereas nouns in the vicinity of a pole take the associated gender, no systematic preference for either gender is identified in between. An example is the affect continuum in German: Whereas nouns denoting introverted affect take feminine gender, nouns associated with extroversion take masculine gender (e.g., introverted affect: die Trauer 'the $\mathrm{fem}_{\mathrm{f}}$ mourning;' extroverted affect: der Zorn 'the mas $_{\text {wrath'). }}$

Phonological gender assignment regularities are relatively well investigated experimentally. In a forcedchoice selection task, Köpcke and Zubin, 1983 presented monosyllabic pseudo-words with two different determiners, of which the more appropriate determiner for the pseudo-word was to be selected. For instance, the

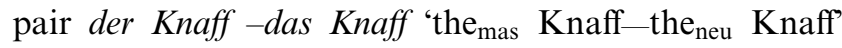
was presented. According to the phonological regularity that $/ \mathrm{kn} /$ in the onset marks masculine gender, der Knaff should be preferred. In most cases, participants preferred the gender predicted by the phonological assignment regularity. Wegener (1995) modified the task to allow for the selection of all three genders, and found similar above-chance preferences for the gender predicted by Köpcke's (1982) phonological regularities. These studies suggest that native speakers make use of phonological regularities when deciding on the gender for a pseudo-word. Recently, Schiller, Münte, Horemans, and Jansma (2003) carried out a study using event-related (brain) potentials (ERPs) to investigate the influence of semantic (biological gender) and phonological factors (phonological gender marking) on gender decision in word comprehension. The ERP data show a strong semantic effect, while the behavioral data also display an effect of phonological marking. Phonological gender assignment regularities thus seem to be part of the assignment system.

Moreover, in a further study, Zubin and Köpcke (1984b) experimentally investigated the semantic affect continuum spanned between the poles introversion 
(feminine gender) and extroversion (masculine gender). They analyzed compounds with -mut, in which (in violation of the last member principle) feminine, masculine, and variable gender assignments occur (der Mut 'the mas $_{\text {courage,' but die Anmut 'the }}$ fem $_{\text {gracefulness,' derl }}$ die Grossmut 'the $\mathrm{fem}_{\mathrm{fem}} / \mathrm{the}_{\mathrm{mas}}$ generosity,' der Hochmut

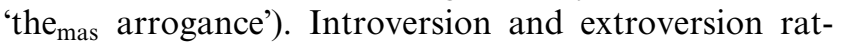
ings for the compounds were obtained. Feminine (or masculine) gender assignment corresponded to high introversion (or extroversion) ratings; variable gender assignment corresponded to intermediate ratings on the introversion-extroversion scale. These data suggest that gender decision for the -mut compounds is based on the word's position in the semantic affect continuum, and thus that the affect continuum and its gender association are represented in the gender assignment system. Thus, there is initial experimental evidence for an elaborate system of regularities within the gender assignment system.

Gender assignment based on form information (e.g., phonological or morphological characteristics; see above) presupposes, however, that the speaker already knows the phonological form of the noun. That is, the phonological form of the noun must be retrieved first before its gender can be derived and before other parts of speech can be marked with gender. In Levelt et al.'s theory of speech production, such a scenario is difficult to imagine since gender information is retrieved on the level of syntactic encoding (the so-called lemma level), i.e., when the processing system is still blind as to what the phonological form of the noun will look like. Furthermore, information exchange between form encoding levels and higher levels, such as the lemma level, is not possible in that model. Note, however, that in many Romance languages the phonological form of the determiner depends on the phonological form (and the gender) of the noun (e.g., il tavolo mas 'the table' vs. lo scienziato $_{\text {mas }}$ 'the scientist'). This shows that there are cases in which the speech production system has to suspend the encoding of earlier units in the utterance until the phonological form of later units has been retrieved. Whether or not there is feedback from form encoding levels to syntactic or semantic levels in speech production is under debate (Dell, 1986; Dell \& O'Seaghdha, 1992 vs. Levelt, 1989, 1992; Levelt et al., 1999).

In the present experiment, we aim to show that regularities in the gender distribution within semantic categories are part of the native speaker's knowledge of the language, and thus part of the gender assignment system. We restrict our investigation to direct gender associations, such as the association of the semantic category predator and masculine gender. If the gender associations of semantic categories can influence gender selection in a forced choice task, it would suggest that speakers have at least tacit knowledge of these gender associations. Alternatively, the finding that semantic categories do not influence gender selection would be more consistent with the lexicalization of gender hypothesis.

\section{The experiment}

To investigate whether or not regularities in the gender system are represented in the speaker's lexicon, we employed a so-called category membership selection task. Participants were first presented with a semantic category, followed by a pair of pseudo-words with different determiners, and thus different gender marking. Participants were then asked to select the determiner (Det) pseudo-word (PW) phrase that fit the category best. For instance, the category Musikinstrument 'musical instrument' was followed by the Det PW phrases der Quachtel 'the mas Quachtel' and die Ruppel 'the fem $_{\text {Ruppel,' and }}$ participants were required to select which of the two Det PW phrases was more appropriate as a category member.

The experimental manipulation was realized in different semantic categories: Some exhibited direct gender-category associations, while others did not. For ease of reference, we refer to the former categories as genderassociated categories and to the latter as non-associated categories. Categories with a regularity calling for masculine gender are masculine categories, those where a regularity calls for feminine gender are feminine categories (see Materials below).

Participants can use three task-related sources for their category membership decision: the pseudo-word itself (e.g., Quachtel), the combination of pseudo-word and determiner (e.g., der Quachtel), and the determiner (e.g., der). To avoid pseudo-words guiding category membership selection, several steps were taken. First, we only used pseudo-words that did not prompt strong gender associations, as suggested by a norming study. Second, we paired pseudo-words so that they were matched for likelihood of category membership, as indicated by a norming study (see Materials below). Finally, pseudo-words were presented with different determiners across participants. Thus, half the participants encountered the pseudo-word Troche as der Troche ('the $\mathrm{mas}_{\mathrm{s}}$ Troche'), the other half as die Troche ('the $\mathrm{fem}_{\mathrm{fem}}$ Troche'). Both pseudo-words within a pair should thus fit equally well into the category, and even if one pseudo-word would be preferred, counter-balancing the gender should avoid systematic effects.

The combination of determiner and pseudo-word is subject to phonological gender preferences. Participants may systematically select the pseudo-word with the determiner that agrees with the phonological gender preference. We took two steps to control for phonological gender associations: First, pseudo-words within a pair were roughly matched for phonological characteristics (both members of each pair were monosyllabic, or 
they were bisyllabic ending with the same pseudo-suffix $-e,-e r$, or $-e l$ ). For instance, Zirf and Gink is a monosyllabic pseudo-word pair, while Belter and Krahler, Mossel and Gremmel, and Troche and Rahle are bisyllabic pseudo-word pairs ending with the pseudo-suffixes $-e r,-e l$, and $-e$, respectively. Second, we used approximately the same number of pseudo-word pairs of each type within each category. Thus, phonological regularities should contribute equally to the determiner selection in each category. If participants prefer die Troche over der Rahle based on the phonological gender preference that polysyllabic words ending in $-e$ are (preferably) feminine, they should do so independent of the semantic category. Whereas this is a systematic influence, it is independent of the experimental manipulation. We expect to find influences of the phonological gender preferences within each type of pseudo-word pair. We do not, however, expect to see influences of phonological gender preferences across categories.

Only decisions based on the determiner are systematically related to the different types of categories. The category membership selection task thus constitutes a gender decision. The experimental question is whether or not the distribution of determiner selection differs by the type of category, i.e., masculine, feminine, or nonassociated. For example, do participants preferably select pseudo-words marked with the masculine determiner $\left(d e r, t_{\text {mas }}\right)$ for masculine categories?

If semantic categories are associated with a particular grammatical gender, then participants should prefer the pseudo-word marked with the associated gender in a forced-choice situation. If the category predator is associated with masculine gender, then participants should select der Troche ('the ${ }_{\text {mas }}$ Troche') with masculine gender

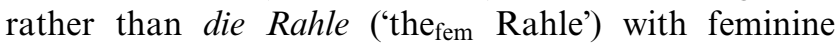
gender as a possible category member. We therefore predict a preference for pseudo-words marked with masculine gender for the masculine categories (stone, spice, and predator), and the opposite, i.e., a preference for pseudo-words marked with feminine gender, for the feminine categories (insect, musical instrument, and fruit). Categories without gender association (body part, kitchen utensil, and tool) should follow yet another pattern.

The null-hypothesis states that semantic categories are not associated with a grammatical gender, and predicts that there is no difference in determiner selection across categories. This prediction holds even if participants use systematic phonological assignment regularities, since this influence was controlled for across categories.

\subsection{Method}

Participants. Twenty-four students of the University of Osnabrück participated in the experiment for course credit. All participants were native speakers of German.

Materials. The materials consisted of nine genderassociated and non-associated semantic categories and of ninety pseudo-word pairs. The semantic categories were determined in a category member-naming task. Fourteen semantic categories taken from Zubin and Köpcke (1984a) were presented to fourteen native speakers of German. These participants were required to name the first ten category members they could think of for each category. On the basis of these results, nine semantic categories were selected, i.e., three masculine, three feminine, and three non-associated semantic categories (see Table 1). Within each category, the number of occurrences for each gender was tested against the overall gender distribution in the German lexicon (see Schiller \& Caramazza, 2003) using a $\chi^{2}$-goodness of fit test (column $\chi^{2}(2)$ in Table 1$)$. When this test was significant, we tested whether or not one gender occurred more often than the others (column $\chi^{2}(1)$ in Table 1). All but one category name had neuter gender; one category name can be used with both neuter and masculine gender.

One hundred twenty native German participants rated 288 orthographically and phonologically legal

Table 1

Category member-naming task: gender distribution

\begin{tabular}{lllllllrr}
\hline Category & & Gender & g.a. & $\mathrm{m}(\%)$ & $\mathrm{f}(\%)$ & $\mathrm{n}(\%)$ & $\chi^{2}(2)$ & $\chi^{2}(1)$ \\
\hline Gestein & stone & $\mathrm{n}$ & $\mathrm{m}$ & $\mathbf{7 5}$ & 10 & 15 & $33.99^{* *}$ & $26.79^{* *}$ \\
Gewürz & spice & $\mathrm{n}$ & $\mathrm{m}$ & $\mathbf{6 1}$ & 28 & 11 & $8.26^{*}$ & $7.76^{* *}$ \\
Raubtier & predator & $\mathrm{n}$ & $\mathrm{m}$ & $\mathbf{6 7}$ & 27 & 6 & $12.25^{* *}$ & $9.90^{* *}$ \\
Insekt & insect & $\mathrm{n}$ & $\mathrm{f}$ & 32 & $\mathbf{6 6}$ & 2 & $20.01^{* *}$ & $11.76^{* *}$ \\
Musikinstrument & musical instrument & $\mathrm{n}$ & $\mathrm{f}$ & 9 & $\mathbf{5 6}$ & 35 & $16.06^{* *}$ & $6.28^{* *}$ \\
Obst & fruit & $\mathrm{n}$ & $\mathrm{f}$ & 7 & $\mathbf{9 3}$ & 0 & $60.97^{* *}$ & $34.72^{* *}$ \\
Körperteil & body part & $\mathrm{m} / \mathrm{n}$ & - & 41 & 34 & 25 & .05 & .87 \\
Küchenutensil & kitchen utensil & $\mathrm{n}$ & - & 42 & 37 & 21 & 16 & 3.82 \\
Werkzeug & tool & $\mathrm{n}$ & - & 49 & 35 & & \\
\hline
\end{tabular}

Gender, gender of the category name; g.a., gender association; m, masculine; f, feminine; n, neuter; -, non-associated; N, number of responses.

${ }^{*} p<.05$.

$p<.01$. 
pseudo-words. Each participant received 24 pseudowords and the nine semantic categories, and had to indicate for each pseudo-word whether or not-based on its phonological form-it could belong to a particular semantic category. Based on this category membershiprating task we removed pseudo-words, which were preferably associated with particular semantic categories solely on the basis of their phonological form. In order to avoid pseudo-words that prompted shared associations across participants, pseudo-word associations were assessed with a pseudo-word definition task: Participants invented "definitions" for an additional 24 pseudowords. Pseudo-words that evoked similar definitions in more than thirty percent of the participants were excluded. From the whole set of pseudo-words, 180 were chosen for the main experiment, and 90 pseudo-word pairs were created, matched on phonological form and category membership ratings (see Table 2 and Appendix A).

Pseudo-words belonged to one of four different word types, i.e., monosyllabic, or bisyllablic ending in the pseudo-suffixes $-e,-e l$, or $-e r$, each having particular gender preferences. The gender preferences were confirmed by a norming task with ten native speakers of German, who selected determiners for the 180 selected

Table 2

Sample pseudo-word pairs

\begin{tabular}{lll}
\hline Körperteil 'body part' & & \\
\hline PW1 & PW2 & Type \\
\hline Trelle & Stisse & e \\
Rese & Linne & e \\
Gindel & Trinchel & el \\
Strummel & Fudel & el \\
Puner & Merder & er \\
Knump & Wott & $\mathrm{m}$ \\
Schlass & Tord & $\mathrm{m}$ \\
Stiß & Stuhn & $\mathrm{m}$ \\
Wolst & Trauch & $\mathrm{m}$ \\
Schlohn & Druht & $\mathrm{m}$ \\
\hline
\end{tabular}

PW: pseudo-word; Type: pseudo-word type; e, el, er: pseudo-suffix $-e,-e l,-e r ;$ m: monosyllabic. pseudo-words. Gender associations and average determiner selection are presented in Table 3 .

Procedure and design. Stimuli were displayed in the upper half of a 17-in. monitor. Each trial consisted of the following events: a fixation star in the center of the experimental screen for $500 \mathrm{~ms}$, a blank screen for $200 \mathrm{~ms}$, the category name for $1000 \mathrm{~ms}$, and then the target pseudo-word pair until the subject responded. The category name was cleared before the target pair was presented. Key-press latencies were measured with $10 \mathrm{~ms}$ accuracy from the onset of the pseudo-word pair. The inter-trial-interval was $1500 \mathrm{~ms}$.

Testing sessions began with a set of 10 practice trials. Practice categories and practice pseudo-word pairs were not used in the experiment. The experiment consisted of 90 trials, 10 for each semantic category. The order of the experimental trials was randomized for each participant individually. Each participant saw each pseudo-word only once. It took approximately $15 \mathrm{~min}$ to complete the experiment.

Pseudo-words were presented with the feminine (die) or the masculine (der) determiner. Within each trial, one pseudo-word was presented with the masculine determiner and one with the feminine determiner. For convenience, pseudo-words presented with the masculine determiner are referred to as masculine pseudo-words, pseudo-words presented with the feminine determiner as feminine pseudo-words. For instance, 'der Rahle' is a masculine pseudo-word, whereas 'die Rahle' is a feminine pseudo-word. Each semantic category was assigned ten pseudo-word pairs (see Table 2 for an example). Across participants, each pseudo-word was presented with both determiners equally often. Location of pseudo-words was also counter-balanced such that each pseudo-word occurred equally often on the left and on the right side of the screen.

Participants were tested individually. They were instructed to read the category name and then the two pseudo-words, and asked to decide which pseudo-word they judged more likely to belong to the semantic category in question as accurately and as quickly as possible. The instructions stressed accuracy over speed. The decision was to be made by pressing a key on the

Table 3

Phonological gender preferences

\begin{tabular}{|c|c|c|c|c|c|c|c|c|c|c|}
\hline \multicolumn{3}{|c|}{ Word types } & \multirow{2}{*}{$\begin{array}{l}\text { Phonological } \\
\text { gender } \\
\text { preferences }\end{array}$} & \multicolumn{3}{|c|}{ Examples } & \multirow[t]{2}{*}{$\mathrm{N}$} & \multicolumn{3}{|c|}{ Norming } \\
\hline Type & Syl & P-suffix & & & Words & Pseudo-words & & M (\%) & $\mathrm{f}(\%)$ & $\mathrm{n}(\%)$ \\
\hline mono & 1 & & $\mathrm{~m}, \mathrm{n}(\mathrm{f})$ & Hals & 'neck' & Pehm & 5 & 60 & 21 & 19 \\
\hline $\mathrm{e}$ & $2+$ & $-e$ & $\mathrm{f}$ & Niere & 'kidney' & Kiere & $1-2$ & 9 & 91 & 0 \\
\hline el & $2+$ & $-e l$ & - & Muskel & 'muscle' & Gudel & $1-2$ & 44 & 46 & 10 \\
\hline er & $2+$ & $-e r$ & $\mathrm{~m}$ & Leber & 'liver' & Mocher & $1-2$ & 84 & 12 & 4 \\
\hline
\end{tabular}

mono: monosyllabic; e, el, er: polysyllabic with pseudo-suffix -e, -el, -er; Syl: number of syllables; P-suffix: pseudo-suffix; N: number of pseudoword pairs per category (total 10); Norming: results (percentage selection) of norming task; m: masculine; f: feminine; n: neuter determiner selected. 
computer keyboard: the $<\mathrm{d}>-\mathrm{key}$ (on the left side of the keyboard) for the pseudo-word presented on the left side of the screen and the $<\mathrm{k}>$-key (on the right side of the keyboard) for the pseudo-word on the right side of the screen. The keys were marked with colored dots. Participants were instructed to keep their hands on the keyboard.

The experiment made use of two independent variables: the gender association of the semantic categories with three levels (masculine, feminine, and non-associated) and the type of the pseudo-word pairs with four levels (monosyllabic, bisyllabic with pseudo-suffix $-e$, $-e l$, or $-e r)$. The dependent measures were the number of selected determiners of each gender (masculine or feminine) and the corresponding response latencies.

\subsection{Results}

Trials with response latencies below $500 \mathrm{~ms}$ were considered outliers ( $1 \%$ of the trials). Furthermore, trials

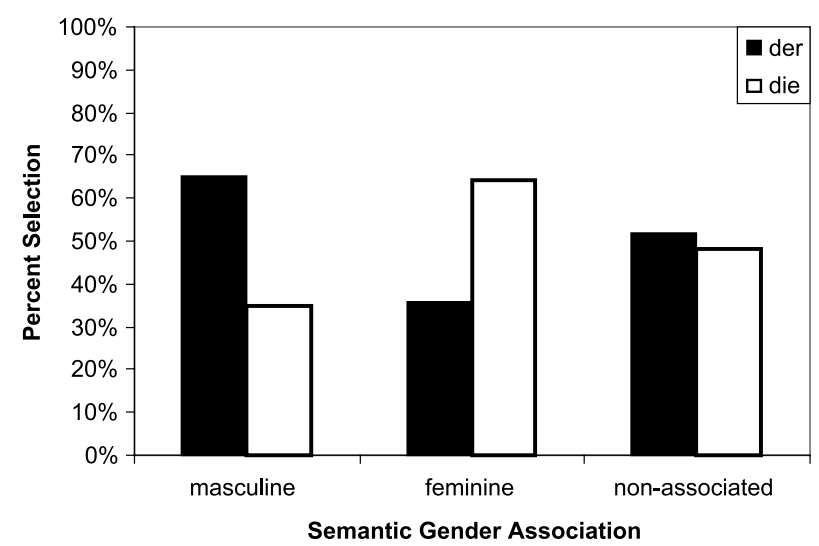

Fig. 1. Gender selection in masculine, feminine, and non-associated categories. In black, masculine gender (determiner 'der' (the mas $)$ ); in white, feminine gender (determiner 'die' $\left(\right.$ the $\left._{\text {fem }}\right)$ ). were excluded from the analysis when the response time differed more than two standard deviations from the mean for a given participant ( $4.3 \%$ of the trials).

For each semantic category, we counted the number of masculine and feminine pseudo-words that participants selected, and tested these numbers against the equal distribution using a $\chi^{2}$-statistic (see Fig. 1 and Table 4). In the non-associated categories, masculine and feminine pseudo-words were chosen equally often $\left(\chi^{2}(1)=1.25\right.$, n.s.), whereas in masculine categories masculine pseudo-words $\left(\chi^{2}(1)=60.82, p<.01\right)$ and in feminine categories feminine pseudo-words $\left(\chi^{2}(1)=53.73, p<.01\right)$ were chosen significantly more often than pseudo-words with the opposite determiner.

Figs. 2-4 show the gender selection for the three types of categories (masculine, feminine, and non-associated) separated by pseudo-word type $-e,-e r$, and $-e l$, respectively. Recall that these pseudo-word types have phonological gender associations (Table 3): the pseudosuffix $-e$ is associated with feminine gender, $-e r$ with masculine gender, and $-e l$ works equally well with both We excluded monosyllabic pseudo-words from this analysis because they combine a range of phonological assignment regularities for all three genders (compare Köpcke, 1982), which we did not match either within pseudo-word pairs or across categories.

The influence of the semantic regularities is most clearly visible within the pseudo-words of type-el (Fig. 4), where no conflicting phonological assignment regularity is at work. Within masculine categories, masculine pseudo-words were preferred $\left(\chi^{2}(1)=8.21, p<.01\right)$, within feminine categories, feminine pseudo-words $\left(\chi^{2}(1)=\right.$ 27.56, $p<.01)$, and in non-associated categories, pseudo-words with both determiners were selected equally often $\left(\chi^{2}(1)=0.56\right.$, n.s.).

The influence of the phonological regularities is most clearly visible in the non-associated categories (right column in Figs. 2 and 3). For type $-e$ pseudo-words, non-associated categories showed a preference for

Table 4

Gender selection (against equal distribution)

\begin{tabular}{|c|c|c|c|c|c|c|}
\hline Category & & g.a. & $\mathrm{N}$ & $\mathrm{m}(\%)$ & $\mathrm{f}(\%)$ & $\chi^{2}(1)$ \\
\hline Gestein & stone & $\mathrm{m}$ & 228 & 64 & 36 & $19.11^{* *}$ \\
\hline Gewürz & spice & $\mathrm{m}$ & 229 & 56 & 44 & 3.18 \\
\hline Raubtier & predator & $\mathrm{m}$ & 234 & 74 & 26 & $53.61^{* *}$ \\
\hline Total m & & & 691 & 65 & 35 & $60.82^{* *}$ \\
\hline Insekt & insect & $\mathrm{f}$ & 221 & 44 & 56 & 2.83 \\
\hline Musikinstr. & musical instr. & $\mathrm{f}$ & 229 & 31 & 69 & $33.05^{* *}$ \\
\hline Obst & fruit & $f$ & 229 & 33 & 67 & $27.25^{* *}$ \\
\hline Total f & & & 679 & 36 & 64 & $53.73^{* *}$ \\
\hline Körperteil & body part & - & 226 & 54 & 46 & 1.13 \\
\hline Küchenutensil & kitchen utensil & - & 220 & 49 & 51 & .16 \\
\hline Werkzeug & tool & - & 229 & 54 & 46 & 1.58 \\
\hline Total - & & & 675 & 52 & 48 & 1.25 \\
\hline
\end{tabular}

g.a., gender association; m, masculine; f, feminine; -, non-associated; N, number of responses. $p<.01$. 


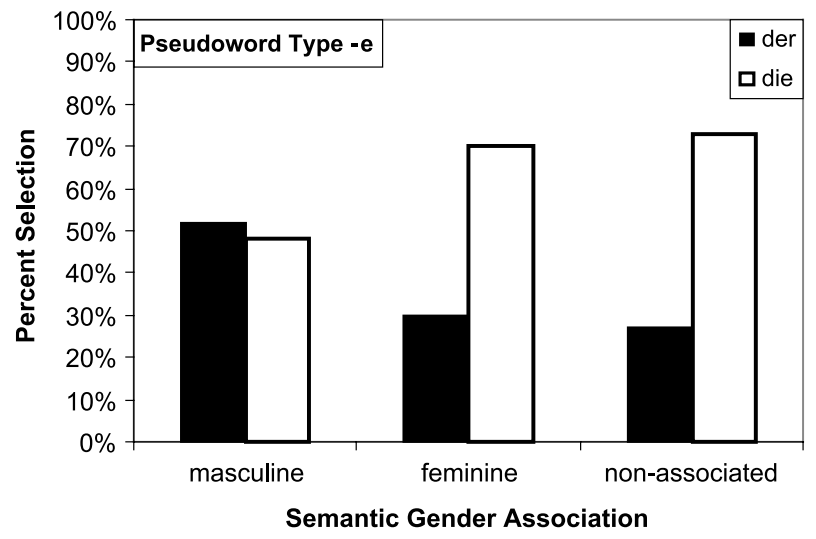

Fig. 2. Gender selection for pseudo-word type $-e$. Phonological gender association is feminine.

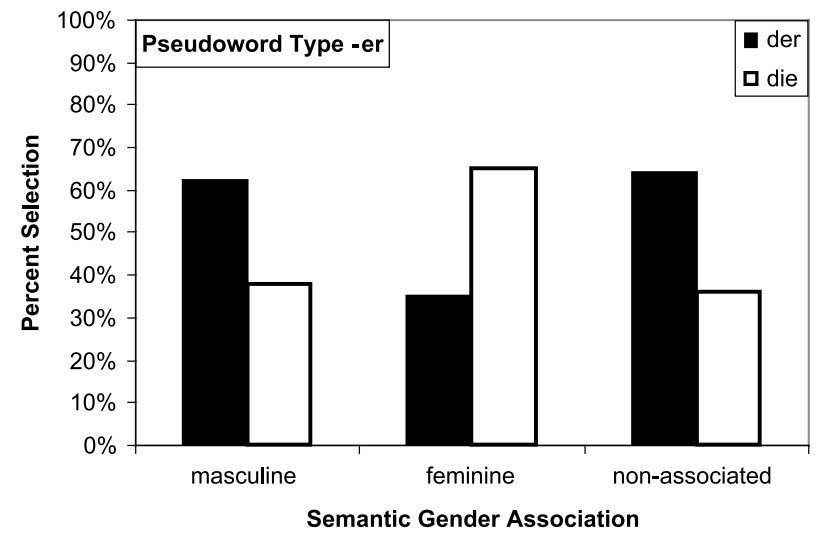

Fig. 3. Gender selection for pseudo-word type -er. Phonological gender association is masculine.

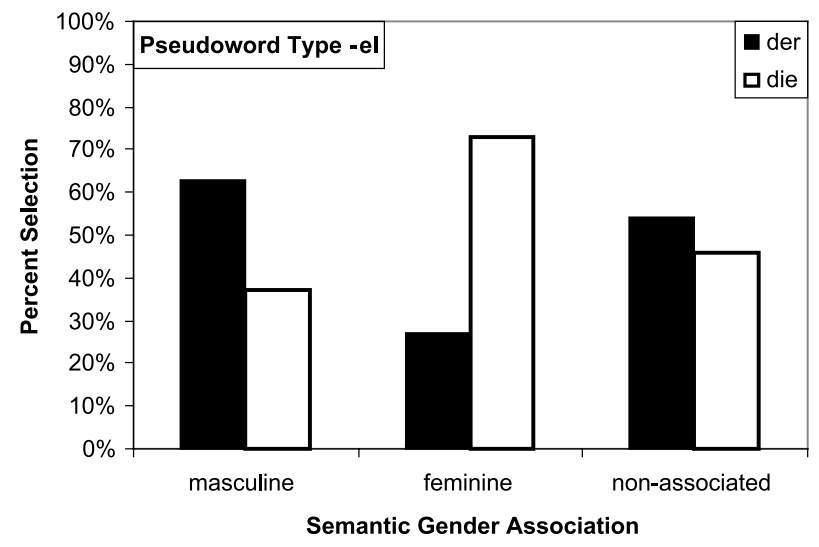

Fig. 4. Gender selection for pseudo-word type -el. No phonological gender association.

feminine gender $\left(\chi^{2}(1)=26.57, p<.01\right)$, and for type -er pseudo-words, they showed a preference for masculine gender $\left(\chi^{2}(1)=8.98, p<.01\right)$.

Both semantic and phonological gender assignment regularities are present for pseudo-words of type-er and of type $-e$ within the gender-associated categories (left and middle columns in Figs. 2 and 3). When semantic and phonological regularities required the same gender, there was a strong preference for the associated gender (masculine categories and type -er pseudo-words: $\chi^{2}(1)=6.76, p<.01$; feminine categories and type $-e$ pseudo-words: $\left.\chi^{2}(1)=21.45, p<.01\right)$. When semantic and phonological regularities required different genders, participants preferred pseudo-words with the determiner congruent with the semantic regularity. This preference failed to reach significance for masculine categories and type $-e$ pseudo-words (masculine categories and type $-e$ pseudo-words: $\chi^{2}(1)=0.22$, n.s.; feminine categories and type $-e r$ pseudo-words: $\left.\chi^{2}(1)=5.88, p<.05\right)$.

The influence of semantic assignment regularities independent of phonological regularities was further assessed by comparing the determiner distribution in gender-associated categories to the distribution in nonassociated categories. When both phonological and semantic regularities were congruent, no difference was observed between the associated and the non-associated categories (feminine categories and type $-e$ pseudowords: $\chi^{2}(1)=0.64$, n.s.; masculine categories and type -er pseudo-words: $\chi^{2}(1)=0.19$, n.s.). When phonological and semantic regularities conflicted, we observed a preference for the semantically associated gender (feminine categories and type - er pseudo-words: $\chi^{2}(1)=$ $24.39, p<.01$; masculine categories and type $-e$ pseudowords: $\left.\chi^{2}(1)=35.19, p<.01\right)$. The preference for the associated gender within type - el pseudo-words did not change (masculine categories: $\chi^{2}(1)=4.01, p<.05$; feminine categories: $\chi^{2}(1)=38.50, p<.01$ ).

The pattern of results within individual gender-associated categories mirrored the category averages with two exceptions (compare Table 4): One masculine (stone) and one feminine category (insect) only showed non-significant preferences for the semantically associated gender.

Reaction times (see Fig. 5) were analyzed only within gender-associated categories. When the predicted gender was selected, responses counted as congruent, otherwise trials were considered incongruent. Reaction times for

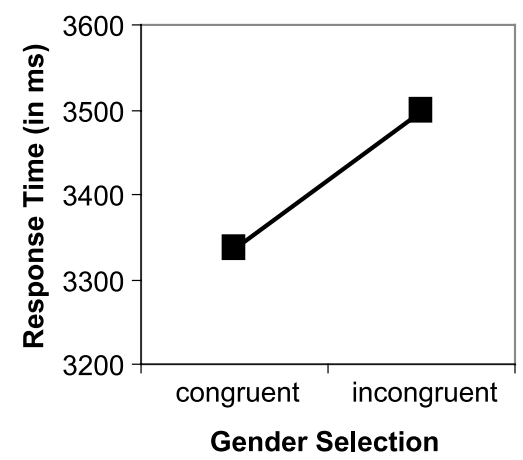

Fig. 5. Response latencies (in $\mathrm{ms}$ ) in the gender selection task for gender-congruent and gender-incongruent trials. 
congruent and incongruent responses were averaged by participant and compared using a paired $t$ test. Congruent responses $(3336 \mathrm{~ms})$ were by $163 \mathrm{~ms}$ faster than incongruent responses $(3499 \mathrm{~ms})$. This difference was significant $(t(23)=2.40, p<.05)$.

\section{Discussion}

The aim of the present study was to experimentally investigate semantic gender assignment regularities. Determiner pseudo-word phrases with congruent determiners were selected as possible members of gender-associated categories more often and faster than determiner pseudo-word phrases with incongruent determiners. Overall, these results indicate that the gender assignment system contains semantic assignment regularities.

Gender selection in the non-associated categories followed phonological assignment regularities. This finding corroborates Köpcke and Zubin (1983) result that the phonologically associated gender is preferred in a forced-choice task. Further, it validates the category membership selection task as a sensitive measure for assignment regularities.

Within the individual gender associated categories, four showed a highly significant preference for the associated gender (masculine: Gestein 'stone,' Raubtier 'predator;' feminine: Musikinstrument 'musical instrument,' Obst 'fruit'). The categories Insekt ('insect') and Gewürz ('spice') showed only a small, non-significant preference for the associated gender. One obvious explanation for the smaller or even absent effect in these two categories is that the assignment system contains only weak (or no) assignment regularities for these semantic categories. The results thus indicate that at least four of the six gender associations (masculine: Gestein 'stone', Raubtier 'predator;' feminine: Musikinstrument 'musical instrument,' $O b s t$ 'fruit') are represented in the assignment system and support the category member selection task. Our findings are hard to account for by a view where the gender for each noun is lexicalized. However, they are congruous with the view that gender is computed.

Gender assignment regularities occur in the semantic, morphological, and phonological domain. How do assignment regularities interact to provide the gender for a specific noun? Köpcke (1982) and Wegener (1995) proposed that assignment regularities follow a strict hierarchy. Whereas Köpcke assumed that the hierarchy runs from semantic to morphological to phonological regularities, Wegener proposed that in the hierarchy first come morphological, then semantic, then phonological regularities. In contrast, Salmons (1993) argued, "no strict hierarchy of rules is possible, but rather only continua based on relative strength or weakness of a particular tendency and the degree of membership in a particular semantic class that a particular word shows" (p. 426). Salmons' view becomes plausible, for instance, when one considers the interaction of phonological and morphological cues and natural gender: In the case of die Wache 'the $\mathrm{fem}_{\mathrm{fem}}$ guard' and das Mädchen 'the ${ }_{\text {neu }}$ girl,' the phonological regularity/morphological rule overrides the semantic regularity (i.e., the natural gender principle).

The findings of the present experiment are congruent with Salmon's view: When phonological and semantic assignment regularities conflicted (as for type $-e$ pseudowords in masculine categories), both assignment regularities worked together such that neither determiner was preferred. In contrast the type-er pseudo-words in feminine categories, where a significant preference for the semantically associated gender (feminine) was obtained.

Assignment regularities could be represented in the lexicon in at least two different ways: in an abstract (i.e., independent of individual category members) or in a concrete (i.e., in terms of collections of category members) manner. Köpcke and Zubin (1983) have argued for a concrete representation. They claimed that assignment regularities are represented as "prototypical groups," that is groups of nouns, which share the same gender and a specific phonological or semantic pattern. For each member of the group, the gender is lexicalized; in addition, the whole group of nouns is closely linked with each other. This approach is similar to Salmons (1993) who argued that "German nouns are somehow grouped within the lexicon at least according to phonetic-phonological shape and semantic characteristics" and that "gender assignment rules for monomorphemic nouns in German must reflect and depend directly on the internal structure of the lexicon" (p. 422).

The structure of the lexicon, as suggested by Levelt's theory (Levelt et al., 1999), is only partially compatible with a concrete representation of assignment regularities. Prototypical groups might be represented in the conceptual network (i.e., the first processing stage in their theory) as strong connections between individual group members. If a member of the prototypical group or the category is activated, the lexical concepts and lemmas of all group members are activated, leading to a pre-activation of the corresponding gender nodes. This pre-activation might account for the observed gender selection patterns. However, the theory contains several features that seem to contradict the use of assignment regularities in on-line production. The theory assumes that grammatical gender only brings a very rudimentary structure onto the lexicon: Nouns with the same gender are connected to the same gender node. However, gender-priming effects, which might empirically reflect this structure, are not reliable (Jescheniak, 1999). Gender retrieval during speech production is accomplished with the help of a uniform mechanism, i.e., the spreading of 
activation from lemma to gender nodes. Lemmas receive their activation from lexical concepts, which allows for a semantic influence on the gender assignment process. However, wordform information (which includes phonological and morphological information) is retrieved only after the corresponding lemma is selected, and feedback from the wordform network is not allowed. Therefore, phonology and morphology cannot influence the gender retrieval process in Levelt's model.

Within Levelt's model, the faster response times for congruent than for incongruent responses can be accounted for by the influence of assignment regularities. Assignment regularities might facilitate the decision by activating the gender node associated with the category. Higher activation of the congruent gender node may reduce the time it takes for the gender node to be activated above the response threshold. However, the data do not indicate whether this is a facilitation effect or an inhibition effect. Thus, the effect of the regularity could be to inhibit the incongruent gender node, and thus increasing the time it takes for this node to get activated above the response threshold. The response latencies for non-associated categories cannot be used as a baseline because different categories were used. The average category membership ratings in the category membership-rating task varied between the experimental categories, indicating that the individual categories differ in their ability to integrate new words. This forbids a direct comparison of response latencies.

Regularities in the assignment system demand a strong structure of the lexicon along the lines of gender, for instance, in form of prototypical groups. Several different gender assignment mechanisms are needed to account for rules, regularities, and exceptional gender assignment. Many types of linguistic information can influence the gender assignment.

We interpreted the preference for the semantically associated gender as a reflection of the influence of semantic gender assignment regularities. An alternative interpretation might be that participants selected determiners in analogy to category members, which would render the results an artifact of the gender distribution within the categories. Recall that gender-associated categories were originally identified by vocabulary analysis, i.e., by finding categories in which most members had the same gender. We confirmed this pattern for the experimental categories in the category membernaming task (Table 1). If participants used the "analogy selection" strategy, they may have retrieved one or more category members, and then selected the determiner pseudo-word phrase that matched the gender of the category member(s). For instance, if the category was Raubtier ('predator'), a masculine category, participants might have come up with words like der Tiger 'the mas tiger,' der Puma 'the mas $_{\text {mama,' der Gepard 'the }}$ mas cheetah,' and der Adler'the ${ }_{\text {mas }}$ eagle.' In analogy, they might have chosen the pseudo-word with the masculine determiner. Since the genders of the generated members should follow the gender distribution within the category, analogy selection would produce a pattern of gender preferences as obtained in the present experiment.

Whereas analogy selection seems a compelling alternative at first glance, there are several issues that analogy selection leaves unresolved. First, if participants used analogy selection, the gender selections should reflect the gender distribution in the category. This should hold across all gender-associated categories. It is hard to explain that of six categories with distributional gender preferences, only four showed highly significant preferences for the associated gender, whereas the remaining two categories only showed nonsignificant preferences. Semantic gender associations account for this finding by assuming weak (or even non-existing) gender assignment regularities for these categories.

Second, analogy selection should depend only on the determiner, not on the pseudo-words involved. We should expect the same pattern of determiner selection for all pseudo-word types. However, determiner selection in the non-associated categories changed with the phonological gender association of the pseudo-words. Analogy selection can account for this finding only by claiming that the pseudo-words influence which category members are retrieved for analogy selection. In particular, the pseudo-word type (pseudo-suffix $-e,-e r$, or $-e l)$ needs to be preserved. This is plausible, since Treiman, Goshwami, and Bruck (1990) showed that for English monosyllabic pseudo-words the final part of the pseudo-word was most salient. However, if pseudoword type is preserved, then the determiner selection should follow the phonological gender preferences in all categories. The category-membership naming task revealed that, within the experimental word types, the category members mainly followed the phonological gender preferences, even if the phonological gender preference contradicted the semantic category association. The predominance of one gender within genderassociated categories was due to a different number of members of each experimental word type, and to category members with different (i.e., non-experimental) phonological forms. Analogy selection should thus reflect the phonological gender preferences, and we should not have observed any difference between gender-associated and non-associated categories. This is contrary to our results. To account for our findings in terms of analogy selection, we would need to propose two different versions of analogy selection, one operating in the non-associated categories (which takes the phonological form into account), and another in the gender-associated categories (which is based on the predominant gender in the category). We would need to claim that participants are using two different strategies, one 
selective to gender-associated categories. These two strategies seem indistinguishable from phonological and semantic assignment regularities, in particular if regularities are represented in the lexicon in concrete form.

A final note of caution in interpreting our findings may be appropriate. The present experiment and other experimental evidence for gender assignment regularities discussed in this paper were based on meta-linguistic tasks. To our knowledge, no evidence from on-line production tasks is available with respect to gender assignment regularities. Our data do not tell us how assignment regularities are represented in the lexicon (i.e., whether they are represented in concrete or abstract form), nor do they answer the question whether or not gender assignment regularities are used in on-line speech production at all. But they do suggest that gender assignment regularities are part of the organizing principles of the lexicon. Future research will need to show how these regularities might influence speaking, as well as how they should influence speech production theory.

\section{Appendix A. Pseudo-word pairs}

\begin{tabular}{|c|c|c|c|c|c|c|c|c|}
\hline \multicolumn{9}{|c|}{ Masculine categories } \\
\hline \multicolumn{3}{|c|}{ Gestein } & \multicolumn{3}{|l|}{ Gewürz } & \multicolumn{3}{|c|}{ Raubtier } \\
\hline \multicolumn{3}{|l|}{ 'stone' } & \multicolumn{3}{|l|}{ 'spice' } & \multicolumn{3}{|c|}{ 'predator' } \\
\hline PW1 & PW2 & Type & PW1 & PW2 & Type & PW1 & PW2 & Type \\
\hline Knumpe & Pölke & $\mathrm{e}$ & Priere & Flerge & $\mathrm{e}$ & Troche & Rahlse & $\mathrm{e}$ \\
\hline Pase & Priebe & $\mathrm{e}$ & Saffe & Monse & $\mathrm{e}$ & Kadel & Rendel & el \\
\hline Tradel & Brongel & el & Zwankel & Gürmel & el & Mossel & Gremmel & el \\
\hline Laister & Solker & er & Fauzel & Trilchel & el & Kraster & Kleuer & er \\
\hline Kninker & Tranner & er & Steimer & Seuer & er & Belter & Krahler & er \\
\hline Klunn & Gach & $\mathrm{m}$ & Kohn & Tahn & $\mathrm{m}$ & Dolk & Wack & $\mathrm{m}$ \\
\hline Luhr & Sult & $\mathrm{m}$ & Fahn & Zand & $\mathrm{m}$ & Brolt & Tahr & $\mathrm{m}$ \\
\hline Pruft & Grost & $\mathrm{m}$ & Spoll & Sart & $\mathrm{m}$ & Polch & Targ & $\mathrm{m}$ \\
\hline Muhr & Knauck & $\mathrm{m}$ & Krausch & Bärz & $\mathrm{m}$ & Zirf & Gink & $\mathrm{m}$ \\
\hline Trunt & Kaun & $\mathrm{m}$ & Kolz & Sperf & $\mathrm{m}$ & $\mathrm{Zau}$ & Kaat & $\mathrm{m}$ \\
\hline
\end{tabular}

Feminine categories

\begin{tabular}{|c|c|c|c|c|c|c|c|c|}
\hline \multicolumn{3}{|l|}{ Insekt } & \multicolumn{3}{|c|}{ Musikinstrument } & \multicolumn{3}{|l|}{ Obst } \\
\hline \multicolumn{3}{|l|}{ 'insect' } & \multicolumn{3}{|c|}{ 'musical instrument' } & \multicolumn{3}{|l|}{ 'fruit' } \\
\hline PW1 & PW2 & Type & PW1 & PW2 & Type & PW1 & PW2 & Type \\
\hline Zumme & Olke & $\mathrm{e}$ & Käste & Gronne & $\mathrm{e}$ & Kiere & Mafte & $\mathrm{e}$ \\
\hline Scheile & Fonsche & $\mathrm{e}$ & Blemme & Deule & $\mathrm{e}$ & Gappe & Sulpe & $\mathrm{e}$ \\
\hline Knissel & Nottel & el & Hadel & Floppel & el & Gudel & Lambel & el \\
\hline Tunzel & Stindel & el & Quachtel & Roppel & el & Fachtel & Blunkel & el \\
\hline Krester & Peuer & er & Zirfer & Dilfer & er & Mocher & Blommer & er \\
\hline Kett & Speuch & $\mathrm{m}$ & Quamm & Kaft & $\mathrm{m}$ & Mest & Mand & $\mathrm{m}$ \\
\hline Knich & Schrant & $\mathrm{m}$ & Hahm & Blahr & $\mathrm{m}$ & Gand & Lauk & $\mathrm{m}$ \\
\hline Trilch & Sier & $\mathrm{m}$ & Moot & Zacht & $\mathrm{m}$ & Jast & Mauch & $\mathrm{m}$ \\
\hline Glehr & Glach & $\mathrm{m}$ & Schrann & Paut & $\mathrm{m}$ & Schrimm & Schwirk & $\mathrm{m}$ \\
\hline Glopf & Schnach & $\mathrm{m}$ & Pucht & Dahl & $\mathrm{m}$ & Pehm & Jund & $\mathrm{m}$ \\
\hline
\end{tabular}

Non-associated categories

\begin{tabular}{|c|c|c|c|c|c|c|c|c|}
\hline \multicolumn{3}{|c|}{ Körperteil } & \multicolumn{3}{|c|}{ Küchenutensil } & \multicolumn{3}{|c|}{ Werkzeug } \\
\hline \multicolumn{3}{|c|}{ 'body part' } & \multicolumn{3}{|c|}{ 'kitchen utensil' } & \multicolumn{3}{|l|}{ 'tool' } \\
\hline PW1 & PW2 & Type & PW1 & PW2 & Type & PW1 & PW2 & Type \\
\hline Trelle & Stisse & $\mathrm{e}$ & Limpe & Kniche & $\mathrm{e}$ & Kampe & Kronse & $\mathrm{e}$ \\
\hline Rese & Linne & $\mathrm{e}$ & Schlohne & Klotte & $\mathrm{e}$ & Sponke & Treite & $\mathrm{e}$ \\
\hline Gindel & Trinchel & el & Dreisel & Welfel & el & Seichel & Spussel & el \\
\hline
\end{tabular}


Appendix A (continued)

\begin{tabular}{|c|c|c|c|c|c|c|c|c|}
\hline \multicolumn{9}{|c|}{ Non-associated categories } \\
\hline \multicolumn{3}{|l|}{ Körperteil } & \multicolumn{3}{|c|}{ Küchenutensil } & \multicolumn{3}{|c|}{ Werkzeug } \\
\hline \multicolumn{3}{|l|}{ 'body part' } & \multicolumn{3}{|c|}{ 'kitchen utensil' } & \multicolumn{3}{|l|}{ 'tool' } \\
\hline PW1 & PW2 & Type & PW1 & PW2 & Type & PW1 & PW2 & Type \\
\hline Strummel & Fudel & el & Seimer & Schraner & el & Knauker & Fulser & er \\
\hline Puner & Merder & er & Straner & Wührer & er & Grutter & Schetter & er \\
\hline Knump & Wott & $\mathrm{m}$ & Spaud & Napp & $\mathrm{m}$ & Prier & Draff & $\mathrm{m}$ \\
\hline Schlass & Tord & $\mathrm{m}$ & Rahl & Steip & $\mathrm{m}$ & Kall & Gocht & $\mathrm{m}$ \\
\hline Sti $\beta$ & Stuhn & $\mathrm{m}$ & Nuld & Tralp & $\mathrm{m}$ & Kluch & Framm & $\mathrm{m}$ \\
\hline Wolst & Trauch & $\mathrm{m}$ & Konk & Schwock & $\mathrm{m}$ & Nald & Schauch & $\mathrm{m}$ \\
\hline Schlohn & Druht & $\mathrm{m}$ & Wuck & Krut & $\mathrm{m}$ & Pahl & Drunsch & $\mathrm{m}$ \\
\hline
\end{tabular}

PW: pseudo-word; Type: pseudo-word type; m: monosyllabic; e, el, er: bisyllabic (pseudo-suffix -e, -el, -er).

\section{References}

Bittner, D. (1999). Gender classification and the inflectional system of German nouns. In B. Unterbeck \& M. Rissanen (Eds.), Gender in grammar and cognition (pp. 1-23). Berlin: Mouton de Gruyter.

Caramazza, A., Miozzo, M., Costa, A., Schiller, N. O., \& Alario, F.-X. (2001). A cross-linguistic investigation of determiner production. In E. Dupoux (Ed.), Language, brain, and cognitive development: Essays in honor of Jacques Mehler (pp. 209-226). Cambridge, MA: MIT Press.

Corbett, G. (1991). Gender. Cambridge: Cambridge University Press.

Dell, G. S. (1986). A spreading-activation theory of retrieval in sentence production. Psychological Review, 93, 283-321.

Dell, G. S., \& O'Seaghdha, P. G. (1992). Stages of lexical access in language production. Cognition, 42, 287-314.

Jescheniak, J. D. (1999). Gender priming in picture naming: Modality and baseline effects. Journal of Psycholinguistic Research, 28, 729737.

Köpcke, K.-M. (1982). Untersuchung zum Genussystem der deutschen Gegenwartssprache ['Investigation of the gender system of contemporary German']. Tübingen: Niemeyer.

Köpcke, K.-M., \& Zubin, D. (1983). Die kognitive Organisation der Genuszuweisung zu den einsilbigen Nomen der deutschen Gegenwartssprache ['The cognitive organization of gender assignment in monosyllabic nouns of contemporary German']. Zeitschrift für germanistische Linguistik, 11, 166-182.

Köpcke, K.-M., \& Zubin, D. (1984). Sechs Prinzipien für die Genuszuweisung im Deutschen: Ein Beitrag zur natürlichen Klassifikation ['Six principles of gender assignment in German: A contribution to natural classification']. Linguistische Berichte, 93, 26-50.

Köpcke, K.-M., \& Zubin, D. (1996). Prinzipien für die Genuszuweisung im Deutschen ['Principles of gender assignment in German']. In E. Lang \& G. Zifonun (Eds.), Deutsch-typologisch. Institut für deutsche Sprache Jahrbuch 1995 (pp. 473-491). Berlin: Walter de Gruyter.
Levelt, W. J. M. (1989). Speaking. From intention to articulation. Cambridge, MA: MIT Press.

Levelt, W. J. M. (1992). Accessing words in speech production: stages, processes and representations. Cognition, 42, 1-22.

Levelt, W. J. M. (2001). Spoken word production: A theory of lexical access. Proceedings of the National Academy of Sciences United States of America, 98, 13464-13471.

Levelt, W. J. M., Roelofs, A., \& Meyer, A. S. (1999). A theory of lexical access in speech production. Behavioral and Brain Sciences, 22, 1-75.

Salmons, J. (1993). The structure of the lexicon: Evidence from German gender assignment. Studies in Language, 17, 411-435.

Schiller, N. O., \& Caramazza, A. (2003). Grammatical feature selection in noun phrase production: Evidence from German and Dutch. Journal of Memory and Language, 48, 169-194.

Schiller, N. O., Münte, T. F., Horemans, I., \& Jansma, B. M. (2003). The influence of semantic and phonological factors on syntactic decisions: An event-related brain potential study. Psychophysiology, 40, 869-877.

Schriefers, H., \& Jescheniak, J. D. (1999). Representation and processing of grammatical gender in language production: a review. Journal of Psycholinguistic Research, 28, 575-597.

Treiman, R., Goshwami, U., \& Bruck, M. (1990). Not all nonwords are alike: Implications for reading development and theory. Memory and Cognition, 18, 559-567.

Wegener, H. (1995). Die Nominalflexion des Deutschen-verstanden als Lerngegenstand ['The nominal inflection of German-seen as a learning matter']. Tübingen: Niemeyer.

Zubin, D., \& Köpcke, K. -M. (1984a). Natural classification in language. A study of the German gender system. Buffalo Cognitive Science Report, 2, SUNY, Buffalo.

Zubin, D., \& Köpcke, K.-M. (1984b). Affect classification in the German gender system. Lingua, 63, 41-96.

Zubin, D., \& Köpcke, K.-M. (1986). Gender and folk taxonomy: The indexical relation between grammatical and lexical categorization. In C. Craig (Ed.), Noun Classes and Categorization. Proceedings of a symposium on categorization and noun classification, Eugene, Oregon, October 1983 (pp. 139-180). Amsterdam: John Benjamins. 